\title{
Laser induced fluorescence spectroscopic sensor for real- time identification of fossil diesel fuel, biodiesel and their blends
}

\author{
Z. Fan $^{1}$, V. Gross ${ }^{1}$, J. Krahl ${ }^{1,2}$ \\ ${ }^{1}$ Coburg University of Applied Sciences and Arts, Technology Transfer Center Automotive Coburg \\ (TAC), Friedrich-Streib-Straße 2, D-96450 Coburg (Germany) \\ ${ }^{2}$ Fuels Joint Research Group, www.fuels-jrg.de \\ Correspondence to: zhu.fan@tac-coburg.com
}

\begin{abstract}
:
A low cost laser induced fluorescence spectroscopic sensor (LFS-sensor) was designed to identify different fossil diesel fuels, biodiesel and biodiesel/diesel fuel blends. This sensor was built from commercial electronic and optical components. It provides the emission spectrum excited at $405 \mathrm{~nm}$. Currently 52 spectra of different diesel fuels, biodiesels, biodiesel blends and gasoline were measured and stored in a reference data bank. Based on this, unknown fuel samples can be identified easily. Furthermore, the LFS-sensor is suitably for in-situ quantification of biodiesel in blends.
\end{abstract}

Key words: Laser induced fluorescence spectroscopy, diesel fuel, biodiesel, fuel sensor.

\section{Introduction}

In the future the variety of fuels from different sources may increase. Since fuel properties have a strong impact on combustion, engine exhaust, and long term stability, the engine control system needs onboard information about the kind of fuel and its composition to optimize the combustion. Sensors based on fluorescence spectroscopy are easy to use and provide quick and accurate results $[1,2,3,4,5$, $6,7,8,9]$. However, the expensive UV-Laser, a rapid spectral-detector and a complex design of fast driver circuits usually restrain the application of this technology, especially in the automotive sector.

In this work we introduce a low cost LFS-sensor prototype consisting of commercially available components. The sensor runs with newly developed data processing methods. The sensor can be used for identification and quantification of diesel fuels, biodiesel and biodiesel blend.

\section{LFS-Sensor and Materials}

The sensing experimental setup is shown in Fig. 1. The sensor contains an excitationsystem, a detector unit (mini-spectrometer), sample holder and the control, data storage and processing unit.

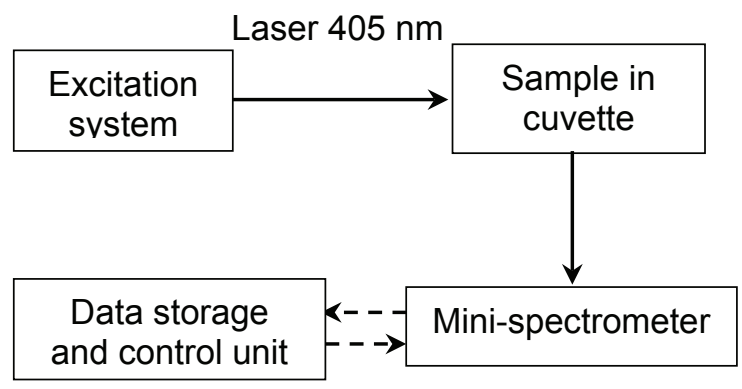

Fig. 1.: Scheme of experimental setup of the LFS-

\section{sensor}

The sensor prototype is shown in Fig. 2. The sensor contains an excitation system (laser driver iC-Haus NZN-1D with blue laser diode PHR-805), a detector unit (Hamamatsu minispectrometer C10988MA-01 with evaluation circuit C11351), sample holder and the data storage and control unit [10].

The excitation system of the experimental LFSsensor contains a laser driver (iC-EVAL-NZN1D; iC-Haus $\mathrm{GmbH}$, Germany) and UVlaserdiode (PHR-805t, Blue Ray harvested, 120 mW; XIEHUA electronic Co., Ltd, China). 


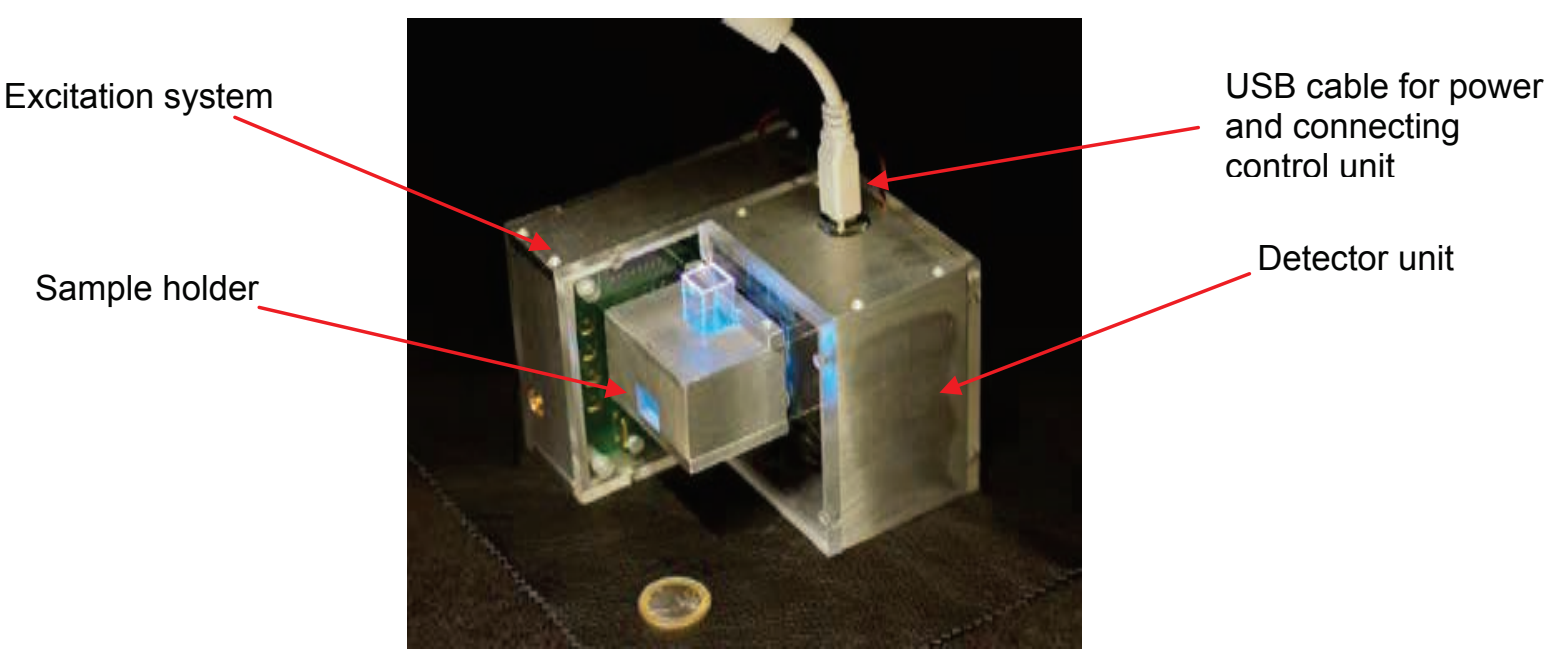

Fig. 2.: LFS-sensor prototype

The iC-EVAL-NZN1D operates from 3.3 to 5.5 $\mathrm{V}$ and can drive $\mathrm{N}, \mathrm{M}$ and P-type laser diodes [11]. This laser driver supports continuous wave CW (for LFS-sensor in this work) or pulse wave PW with the switching frequencies up to 155 $\mathrm{MHz}$ and laser currents up $300 \mathrm{~mA}$. The UVlaser unit comprises a photodiode integrated, a collimating optics (focus: $4.5 \mathrm{~mm}$, quartz lenses for $405 \mathrm{~nm}$, anti-reflection coating, external thread: $\mathrm{M} 9 \times 0.5 \mathrm{~mm}$ ) and an aluminum passive cooler (internal thread: M9 x $0.5 \mathrm{~mm}$ ). The excitation system was housed in a box which consists of an aluminum frame with two acrylic covers [10].

The mini-spectrometer (C10988MA-01) was delivered by Hamamatsu Photonics K. K., Germany. The optical component layout of the mini-spectrometer is shown in Fig. 3. This spectrometer is a CMOS linear image sensor. The thumb size is $27.6 \times 16.8 \times 12 \mathrm{~mm}$ and weights ca. $9 \mathrm{~g}$. There are 256 pixels and each pixel size is $12.5 \times 1000 \mu \mathrm{m}$. Its spectral range is from $340 \mathrm{~nm}$ to $750 \mathrm{~nm}$ and the spectral resolution is $14 \mathrm{~nm}$. Besides a CMOS image sensor chip integrated with an optical slit by etching, the mini-spectrometer employs a grating that is formed on a convex lens by nano-imprint. This has made the unit very compact. The light is diffracted by the reflective grating, and the separated wavelengths impinge on the CMOS linear image sensor's pixels [12].

The LFS-measurement was performed on diesel fuels in an acryl cell. The control, monitoring and data storage unit is a Hamamatsu software (HMSEvaluation). With it the measurement of the fuels can be controlled and the measuring spectra can be real time monitored.
The measurement results are compared with the reference value in the database to identify the fuel sample. Also the biodiesel concentration can be determined by measuring the fluorescence of the fluorophores in biodiesel.

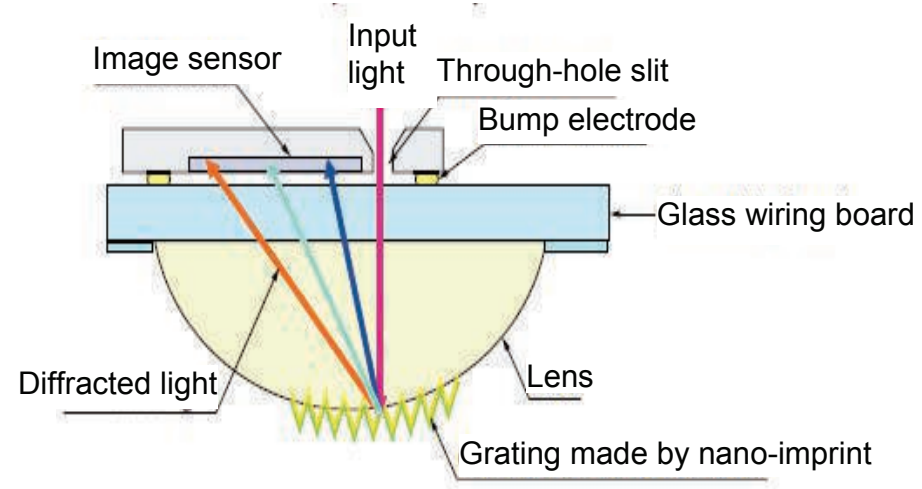

Fig. 3. Optical component layout of the minispectrometer (C10988MA-01) [12]

\section{Fuels}

The LFS-sensor was used to measure the fluorescence spectra of 52 different fuels. The commercial gasoline (Shell super E10: gasoline with $10 \%$ ethanol), fossil diesel (Aral Ultimate Diesel: biodiesel free) and biodiesel blends (Walther diesel fuel: up to $7 \%$ biodiesel) were bought from filling stations or delivered by mineral oil or biofuel companies (e.g. Shell, Aral, Walther, China National Petroleum Corporation (CNPC)) in Europe and China. Hydrotreated vegetable oil (HVO) was delivered from Neste Oil. CEC reference fossil diesel fuel (DF) was from Haltermann (ca. $25 \%$ aromatics). Biodiesel, (rapeseed oil methyl ester (RME), soybean oil methyl ester (SME) and palm oil methyl ester (PME)) were from ASG-Analytik. 


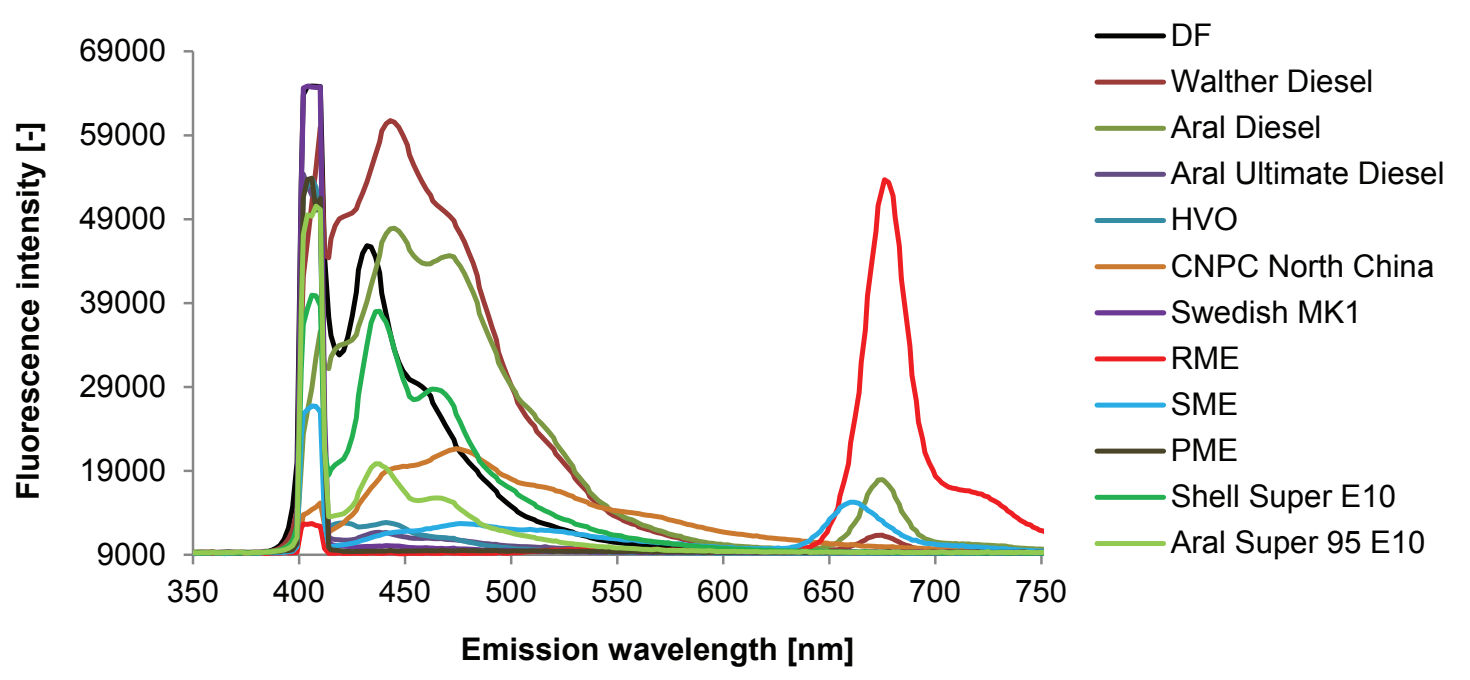

Fig. 4.: Fluorescence spectra of twelve different fuels by LFS-sensor, excitation at $405 \mathrm{~nm}$

Rapeseed oil is the most important vegetable raw materials for biodiesel in Germany [13]. To test the ability to quantify RME in biodiesel/diesel fuel blends by LFS-sensor, we prepared different fuel blends (B0, B1, B2, B3, $B 4, B 5, B 6, B 7, B 8, B 9$ and B10) from DF and RME by ourselves.

\section{Results}

\section{$>$ Identification of diesel fuels}

Fig. 4 shows laser-induced fluorescence spectra for twelve different fuels at an excitation wavelength of $405 \mathrm{~nm}$. These spectra represent fluorescence intensities as function of emission wavelength (x-axis).

The fluorescence spectra of fuels are most likely mainly induced by fluorophores from characteristic fuel molecules and especially additive packages. The figure demonstrates that $405 \mathrm{~nm}$ excitations wavelength enables to identify fossil diesel fuel (DF), biodiesel (RME, SME, PME), conventional diesel fuels (Walther Diesel, Aral Diesel), premium diesel fuel (Aral Ultimate Diesel), hydrotreated vegetable oil (HVO) as well as diesel fuel from other countries (CNPC North China, Swedish MK1) and gasoline (Shell Super E10, Aral Super 95 E10).

\section{$>$ Determination of biodiesel concentration in biodiesel/ diesel fuel blends}

According to Beer's law under the conditions which include analyzed fluorophore at low concentration in homogeneous solution with negligible matrix interference, and under constant experimental conditions (e. g. temperature, pressure, $\mathrm{pH}$ ), a simple relationship between fluorescence intensity $I$ at a given emission wavelength and analyzed biodiesel concentration $B X(X$ is the percent biodiesel blended) is given by

$I=a \cdot B X+b$

Fig. 5 shows that at $405 \mathrm{~nm}$ excitation wavelength, the fluorescence derives from the reference fossil diesel fuel (main fluorophors are polycyclic aromatic hydrocarbons $\mathrm{PAH}$ ) and RME (main fluorophores are Vitamin $\mathrm{E}$ and Chlorophylls) [14]. The emission band with the emission maximum at $432 \mathrm{~nm}$ belongs to $\mathrm{PAH}$ in fossil diesel fuel. The fluorescence at the emission wavelength of $673 \mathrm{~nm}$ was attributed to chlorophylls in RME $[14,15,16,17,18,19$, 20].

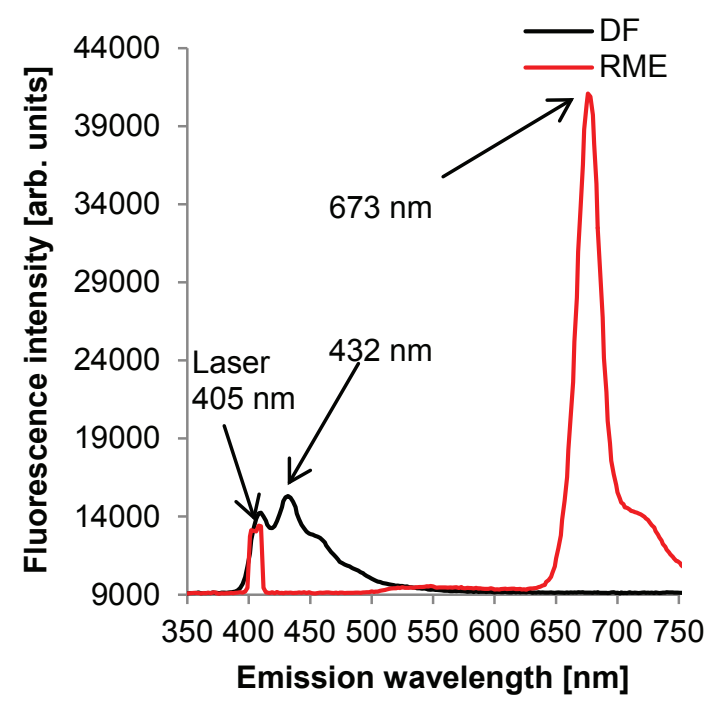

Fig. 5.: Emission spectra of DF and RME, excitation at $405 \mathrm{~nm}$ 
The spectra of the biodiesel blends between B0 to B10 are shown in Fig. 6. It is clear that the fluorescence intensity at the emission wavelength of $432 \mathrm{~nm}$ decreased in general with the increase of biodiesel concentration. In contrast, the fluorescence at the emission wavelength of $673 \mathrm{~nm}$ increased with the increase of biodiesel concentration.

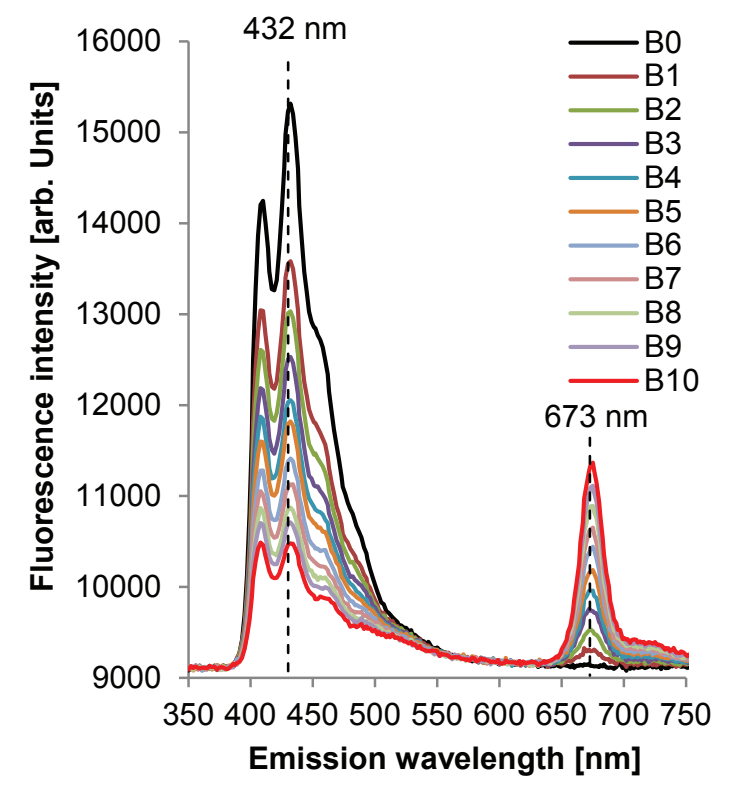

Fig. 6.: Emission spectra of biodiesel blends (B0-

B10) from DF and RME, excitation at $405 \mathrm{~nm}$

To unify the measurement data the fluorescence intensity have been reduced by the background signal and then normed by the following equation:

$$
I_{673, \text { norm }}=\frac{I_{673}}{I_{R M E, 673}} ; \quad I_{432, \text { norm }}=\frac{I_{432}}{I_{D F, 432}}
$$

$I_{\text {RME,673: the intensity of pure RME at emission }}$ wavelength of $673 \mathrm{~nm}$

$I_{673}$ : the intensity of blends at emission wavelength of $673 \mathrm{~nm}$

$I_{D F, 432}$ : the intensity of pure DF at emission wavelength of $432 \mathrm{~nm}$

$I_{432}$ : the intensity of blends at emission wavelength of $432 \mathrm{~nm}$

$I_{673, \text { norm: }}$ the nominated intensity of blends at emission wavelength of $673 \mathrm{~nm}$

$I_{432, \text { norm: }}$ the nominated intensity of blends at emission wavelength of $432 \mathrm{~nm}$

The nominated fluorescence intensity at the emission wavelength of $432 \mathrm{~nm}$ and $673 \mathrm{~nm}$ is plotted against biodiesel concentration (see Fig. 7). A nearly linear dependency between the fluorescence intensity and biodiesel concentration becomes obvious at $673 \mathrm{~nm}$. The simple linear regression of the data with
Equation (1) shown in Fig. 7 (blue solid line) led to a coefficient of correlation $\mathrm{R}^{2}$ of 0.9991 and an angular coefficient of 0.007631 .

However, the $432 \mathrm{~nm}$ wavelength revealed a different shape: Due to the strong secondary absorption of the fluorescence light at this wavelength by RME the fluorescence intensities do not follow linearly the biodiesel concentration. Therefore, the quenching effect must be taken into account. The static quenching effect can be described by the SternVolmer constant [21, 22, 23, 24]:

$\frac{I_{0}}{l}=\frac{k \cdot[F L]}{l}=1+K_{S V} \cdot[Q]$

[FL]: the fluorophore concentration which is similar to concentration of DF [Q]: the quencher concentration which is similar to concentration of biodiesel RME $I_{0}$ : the fluorescence intensity without quenching, which has a linear dependency to the fluorophore concentration with a factor $k$ $l$ : the fluorescence intensity with quenching $K_{S V}$ : the Stern-Volmer constant

By fitting the Stern-Volmer equation with the experimental data, the two constants were determined: $K_{S V}=25.9482$ and $k=0.9802$. In Fig. 7 , it is shown that the Stern-Volmer equation can be very well adapted to the experimental data (black solid line with $R^{2}=$ 0.9948).

The results demonstrate that with LFS-sensor at the excitation wavelength of $405 \mathrm{~nm}$ the fluorescence intensities at the emission wavelengths of $432 \mathrm{~nm}$ and $673 \mathrm{~nm}$ enable the quantification of diesel fuel and biodiesel in fuel blends.

\section{Conclusion}

A LFS-sensor was designed, manufactured and tested. The sensor was used to measure the fluorescence spectra of fossil diesel fuels, biodiesels, biodiesel blends and gasoline at excitation wavelength of $405 \mathrm{~nm}$. It shows that all fuels can be identified and distinguished.

Compared to the traditional analytical methods, such as GC/MS, HPLC etc., the LFS-sensor is extremely cheap and small, can also provide fast identification of fuels, and usually does not require sample preparation.

In addition, by measuring of fluorescence intensity at the characteristic emission wavelengths (432 nm and $673 \mathrm{~nm}$ ) the easy and quick determination of the content of diesel fuels and biodiesel RME in the blends can be achieved. 


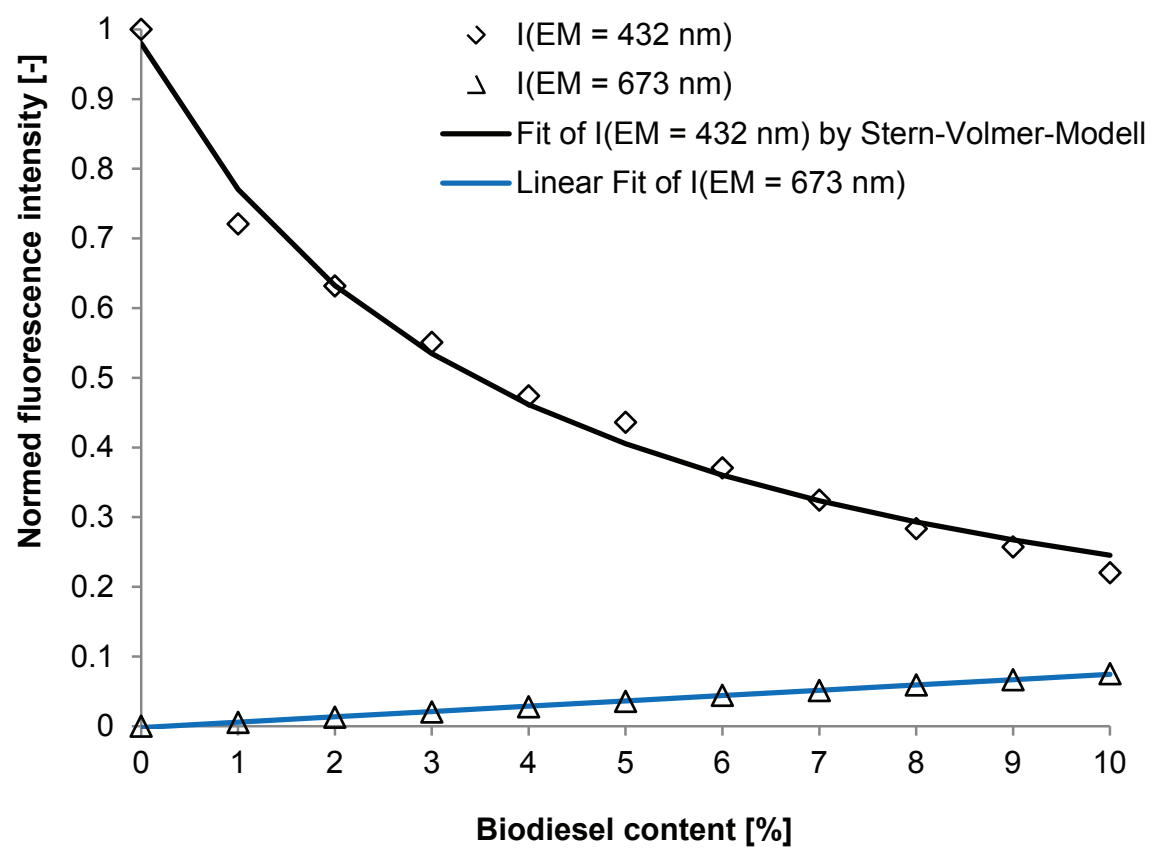

Fig. 7.: Fitting of fluorescence intensity for the given emission wavelengths of $432 \mathrm{~nm}$ and $673 \mathrm{~nm}$ versus biodiesel content in a biodiesel blend

In all, the sensor can be used to control fuel quality in process engineering or fuel supply, to optimize the combustion process in vehicle and e.g. to reduce emission by adapting the motor management to the fuel.

\section{References}

[1] R. Barbini, R. Fantoni, A. Palucci, S. Ribezzo, H. J. L. van der Steen, Spectral and time resolved measurements of pollutants on water surface by a XeCL laser fluorosensor, EARSeL Advances in Remote Sensing 1(2), 46-51 (1992); doi: 10.1117/12.46948

[2] P. Camagni, A. Colombo, C. Koechler, N. Qi, P. Omenetto, G. Rossi, Fluorescence response of mineral oils: spectral yield vs absorption and decay time, Applied Optics. 30(1), 26-35 (1991); doi: 10.1364/AO.30.000026

[3] T. Hengstermann, R. Reuter, Lidar fluorosensing of mineral oil spills on the sea surface, Appl Opt. 29(22), 3218-3327 (1980); doi: 10.1364/AO.29.003218

[4] B. M. Kulkarni, B. G. Pujar, S. Shanmukhappa, Investigation of acid oil as a source of biodiesel, Indian $J$ Chem Technol. 15, 467-471 (2008)

[5] S. Patsayeva, V. Yuzhakov, V. Varlamov, R. Barbini, R. Fantoni, C. Frassanito, A. Palucci, Laser spectroscopy of mineral oils on water surface, EARSeL eProceedings. 1, 106-115 (2000)

[6] J. Steffens, E. Landulfo, L. C. Courrol, R. Guardani, Application of fluorescence to the study of crude petroleum, J Fluoresc. 21, 859-864, doi: 10.1007/s10895-009-0586-4 (2011)

[7] M. D. Scherer, S. L. Oliveira, S. M. Lima, L. H. Andrade, A. R. Caires, Determination of the biodiesel content in diesel/biodiesel blends: a method based on fluorescence spectroscopy, J Fluoresc. 21 (3), 10271031, doi: 10.1007/s10895-010-0815-x (2011)

[8] A. Zawadzki, D. S. Shrestha, B. He, Biodiesel blend level detection using ultraviolet absorption spectra, Trans ASABE 50(4), 1349-1353 doi:10.13031/2013.23612

[9] C. Y. Ralston, X. Wu, O. C. Mullins (1996) Quantum yields of crude oils, Appl Spectrosc. 50, 1563-1568 (1996); doi:10.1366/0003702963904601

[10] iC-Haus laser diode driver, information on: http://www.ichaus.de/upload/pdf/NZN_datas heet_C1en.pdf (2015)

[11] Hamamatsu Mini-spectrometers, information on :

http://www.hamamatsu.com/resources/pdf/s sd/c10988ma-01_etc_kacc1169e.pdf (2015) 
[12] V. Gross, Auslegung eines Fluoreszenzsensors zur Unterscheidung von Biodieselkraftstoffen, Diploma theses, p101, Coburg University of Applied Sciences and Arts, Coburg, Germany (2014)

[13] UFOP report: Raw material basis for biodiesel components in diesel fuels, Berlin, information

on: http://www.ufop.de/english/news/ufop-fillingstation-study-rapeseed-oil-determines-theraw-material-mix-in-the-winter/ (2013)

[14] Z. Fan, O. Schröder, F. Bär, M. Eskiner, K. Schaper, J. Krahl, Abschlussbericht zum Forschungsvorhaben Fluoreszenzspektroskopische Charakterisierung und Identifizierung von Kraftstoffgemischen zur Entwicklung eines Kraftstoffsensors (TRLFS), Förderkennzeichen: 22004710, Coburg University of Applied Sciences and Arts, Coburg, Germany (2013)

[15] D. M. Gazdaru, B. Iorga, Characterization of the quenching of chlorophyll fluorescence by carotene using the non-linear analysis, Photosynthetica 39(4), 607-609 (2001); doi:10.1023/A:1015672516537

[16] E. Sikorska, A. Romaniuk, I. V. Khmelinskii, R. Herance, J. L. Bourdelande, M. Sikorski, J. Kozioł, Characterization of edible oils using total luminescence spectroscopy, $J$ Fluoresc. 14, 25-35 (2004); doi: 10.1023/B:JOFL.0000014656.75245.62

[17] E. Sikorska, T. Gorecki, I. V. Khmelinskii, M. Sikorski, J. Kozioł, Classification of edible oils using synchronous scanning fluorescence spectroscopy, Food Chem. 89, 217-225 (2005), doi: 10.1016/j.foodchem. 2004.02.028

[18] E. W. Hammond, Analysis Tocopherols and Tocotrienols, Lipid Tech. 10, 86-88 (1998)

[19] E. L. Syväoja, V. Piironen, P. Varo, P. Koivistoinen, K. Salminen, Tocopherols and tocotrienols in finish foods: oils and fats, $J$ Am Oil Chem Soc. 63, 328-329 (1986); doi:10.1007/BF02546039

[20] A. Cert, W. Moreda, M. C. Pe'rez-Camino, Chromatographic analysis of minor constituents in vegetable oils, J. of Chromatography. A 881, 131-148 (2000); doi:10.1016/S0021-9673(00)00389-7

[21] M. R. Eftink, Fluorescence quenching: theory and applications, in J. R. Lakowicz (ed.), Topics in Fluorescence spectroscopy, Plenum, New York and London, 53-126 (1991); doi: 10.1007/0-306-47058-6_2

[22] Z. Lakos, A. Szarka, L. Koszorus, B. Somogyi, Quenching-resolved emission anisotropy: a steady state fluorescence method to study protein dynamics, J. Photochem. Photobiol. B 27, 55-60 (1995)
[23] J. R. Lakowicz, Principles of fluorescence spectroscopy, Plenum, New York, chapter 9 (1983); ISBN: 0306412853

[24] B. Somoogyi, Z. Lakos, Protein dynamics and fluorescence quenching, J. Photochem. Photobiol. B 18, 3-16 (1993); doi:10.1016/ 0304-5102(88)85040-5 